\title{
A Study on the Effectiveness of the Horizontal Shading Device Installation for Passive Control of Buildings in South Korea
}

\author{
Seok-Hyun Kim, ${ }^{1}$ Kyung-Ju Shin, ${ }^{2}$ Hyo-Jun Kim, ${ }^{1}$ and Young-Hum Cho $^{3}$ \\ ${ }^{1}$ Department of Architectural Engineering, Graduate School of Yeungnam University, Gyeongsan 38541, Republic of Korea \\ ${ }^{2}$ SINIL E\&C, Daegu, Republic of Korea \\ ${ }^{3}$ School of Architecture, Yeungnam University, Gyeongsan, Gyeongbuk 38541, Republic of Korea \\ Correspondence should be addressed to Young-Hum Cho; yhcho@ynu.ac.kr
}

Received 20 October 2016; Accepted 12 December 2016; Published 9 January 2017

Academic Editor: Geun Y. Yun

Copyright (C) 2017 Seok-Hyun Kim et al. This is an open access article distributed under the Creative Commons Attribution License, which permits unrestricted use, distribution, and reproduction in any medium, provided the original work is properly cited.

\begin{abstract}
In South Korea, the evaluation criteria for installing shading devices are defined by regulations, but the standards of design methods are not clearly established. The installation of shading devices has become mandatory for some public buildings due to revised regulations. Therefore, a design of horizontal shading device is required, and indoor environmental problems which may occur due to their installation should also be taken into consideration. This research aimed to propose a design which takes into account the energy consumption which may occur if the horizontal shading device is installed and suggests an improved design method of horizontal shading devices when they are installed. Consequently, it was confirmed that as the protrusion of the horizontal shading device becomes longer, the incoming daylight is reduced and the indoor intensity of illumination becomes lower, and thus more lighting energy may be consumed in a room where the shading device is installed than in the one where it is not. Therefore, annual energy consumption was calculated by applying the lighting control and it was found that the total energy consumption decreased by the reduction of air-conditioning and fans and lighting energy consumption.
\end{abstract}

\section{Introduction}

In 2013, the government of South Korea revised the "Framework Act on Low Carbon, Green Growth" in order to reduce such energy consumption, thereby establishing the requirements for composition of green architectures. And they legislated "The Support System for Composition of Green Architectures" in order to realize low carbon green growth and contribute to improving the welfare of the people through the reduction of greenhouse gas emissions of buildings and expansion of green architectures. The government has managed this new law through continuous revisions of it.

Recently, the insulation performance of windows has become more important because the area of the window at theee building envelope was increased. So, it has lower performance than the insulation. Most efforts to improve this performance have been based on thermal insulation and air tightness, when actually the cooling load is affected by the solar radiation transmitted through windows in buildings. For energy saving, solar radiation should be blocked by a shading device in the summer season. But the heat gain through the window from solar radiation is required for heating energy saving in the winter season. Therefore, the consideration of control device of solar radiation is required by regulations and designers. The Korean government has provided guidelines and regulations for window installation. Shading devices are defined by regulations in Korea. The guidelines and regulations for reducing the energy consumption in buildings are not perfect, and any study related to windows must adhere to the guidelines and regulations of the Korean government. The horizontal shading device has a simple concept and easy installation procedure, considered to be efficient in energy saving in building heating and cooling energy consumption. Figure 1 shows the concept of horizontal shading device installation.

This study analyzed and compared the indoor energy consumption according to the performance of windows installed on the outer walls of office buildings and analyzed the indoor energy consumption concerning the installation 


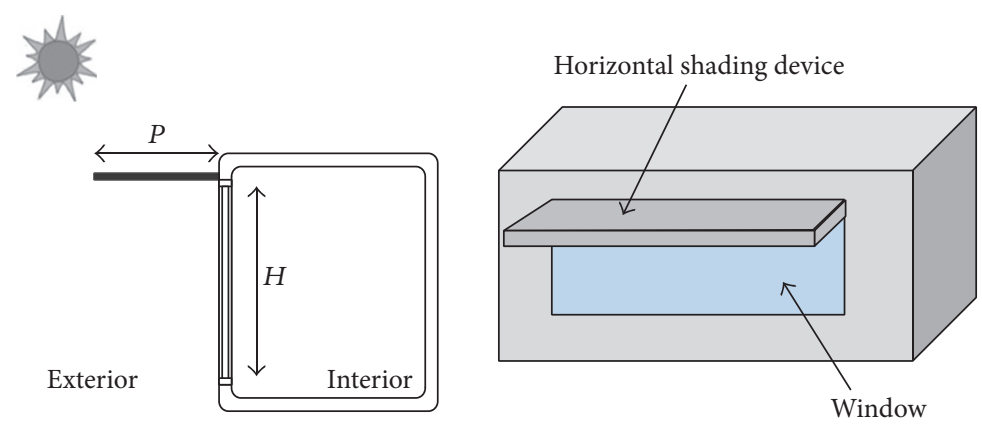

FIGURE 1: Concept of horizontal shading.

of the horizontal shading device, one of the shading devices which are currently installed mandatorily. Taking various window-to-wall ratios and window performance differences into consideration, the unit space was set, and the energy consumption of the unit space according to the window-towall ratios was calculated using simulation. In addition, the calculated figure of the protruding length of each horizontal shading device was applied, the indoor energy consumption was calculated by means of simulation, and the results were analyzed. By these results of analysis, this paper proposed an elementary chart of design of horizontal shading device installation.

\section{Literature Review}

2.1. Law and Regulation on the Solar Control Systems. "The Support System for Composition of Green Architectures" was enacted to establish the requirements for the composition of green buildings in accordance with the "Framework Act on Low Carbon, Green Growth," which realized the low carbon green growth and contributed to improving the welfare of the people through the reduction of greenhouse gas emissions and the expansion of green buildings. The law was revised and new provisions were introduced in 2015. Above all, the provision which prescribes "the scope of buildings for which the solar control façade system for blocking solar radiation is mandatory" was newly established within "The Support System for Composition of Green Architectures" [1]. In addition, the provision concerning "the materials of the outer wall which require the installation of shading devices" was newly added to define the areas where the installation of the solar control façade system is necessary and it states that the materials prescribed by "The Support System for Composition of Green Architectures" are glass or plastic for lighting. This concerns the openings for incoming daylight as well as common glass windows. This shows the importance of energy saving related to the openings made for natural lighting in buildings [2]. To determine the criteria and methods of the conversion of existing architectures into green buildings in accordance with "The Support System for Composition of Green Architectures" and "Enforcement Regulations of the Support System for Composition of Green Architectures," "Standards of Energy Performance Improvement of Existing Architectures" was implemented in 2015.
The implementation of this new law shows the importance of energy-saving efforts of the existing buildings [3]. In addition, for the purpose of efficient energy management of buildings in accordance with "The Support System for Composition of Green Architectures," the "Building Energy Conservation Design Standards" has been revised in order to establish the criteria for energy-saving designs concerning the prevention of heat loss and the standards for writing energy-saving plans and design review reports and determine the items related to the relaxation of building standards for promotion of construction of green architectures [4]. The revised law states that the solar control façade system, solar transmittance, and window area ratio should be considered in a building design in order to reduce cooling and heating loads due to incoming solar heat and that if shading devices are installed, safety should be reviewed against rain, wind, snow, or icicles and accidents like a fire, and possible damage to the surrounding buildings affected by light reflection should also be taken into consideration. In addition, it states that the solar control façade system should be installed as defined by the legal standards so as to control the direct solar radiation which reaches the window. This shows the need for the installation of the solar control façade system for energy saving of buildings [4]. Shading devices are defined in the "Building Energy Conservation Design Standards" as follows: "They are devices installed for the purpose of reducing solar heat coming into the room and they are divided into external shading devices, internal ones, and the ones between window glasses according to the installation positions. They can be divided into fixed ones and movable ones according to whether they can be moved or not" [5]. The shading devices are part of the solar control façade systems defined in the same regulations, and their installation has become mandatory for some public buildings due to the regulations revised in 2015. A common shading device refers to the one that creates a pleasant indoor environment by controlling incoming solar radiation appropriately or blocking it, thereby reducing the cooling or heating load of the room and selectively allowing natural lighting and views. Although the daylight that comes through the window glass contributes to heating load reduction in winter, it can cause a significant increase of cooling loads in summer due to the indoor heat gain acquired through solar radiation. Therefore, it is possible to reduce energy consumption and create a comfortable indoor environment by applying shading 
devices and complementing the weak points of windows in summer [6].

\subsection{A Review of Previous Studies on the Application of Hori-} zontal Shading Devices. Various studies were previously conducted on shading devices, and the previous research can be summarized as follows: Al-Tamimi and Fadzil [7] conducted research upon the possibility of applying shading devices in order to lower the temperatures of tropical highrise residential buildings. Focusing on the hot and humid climate of Malaysia and the indoor temperature control effect for high-rise residential buildings, they analyzed optimal external shading devices that can reduce incoming heat and consequently optimize energy consumption, using simulations. Kim et al. [8] conducted an energy simulation using a computer model created for residential buildings in Korea based on practicality in order to introduce optimal external shading devices by conducting comparative research of thermal performances of the external shading devices of residential buildings. Palmero-Marrero and Oliveira [9] investigated the effect of a louvered sunshade system, evaluated the performance of shading devices according to orientations and situations, and analyzed the effects of the louvered sunshade system which vary depending on diverse factors. Datta [10] analyzed the energy consumption of buildings by means of the TRANSYS simulation and conducted a comprehensive analysis on appropriate shading device models in order to investigate the effects of thermal performance fixed horizontal shading devices applied to buildings. Kim et al. [11] analyzed the cooling and heating energy consumption of office buildings in Korea when horizontal shading devices or Venetian blinds were used and analyzed suitable shading devices according to regions and orientations. Lee et al. [12] carried out the research on climate index development using the local weather data in order to make it possible to understand the characteristics of the local climate in the early design stage and confirm the validity of shading devices which can be judged by the user. Kim et al. [13] evaluated cooling load decreases by assessing the reduction of cooling loads in the office buildings with a large cooling load in order to confirm the effect of an efficient design of shading devices upon office buildings. This study aimed to confirm that shading devices are installed for the purpose of improving the visual comfort of indoor building occupants by blocking excessive sunlight and allowing adequate daylight to come through windows. Tzempelikos and Athienitis [14] studied the control of shading devices for the cooling and lighting control of buildings and provided guidelines on the performance of shading devices and the design of the window glass ratio. They conducted analyses for the purpose of providing the guidelines on properties, shading control, and how to select the glass ratio of the façade. Choi et al. [15] developed a parameter design methodology that combines heat and the design pyramid by performing a thermal analysis and investigating a parameter design methodology and conducted research upon a parametric louver design system for optimization of the shape of the louver. Karlsen et al. [16] developed a solar shading control strategy for Venetian blinds applied on office buildings in cold climates in order to achieve acceptable energy use and indoor environmental performance. Khoroshiltseva et al. [17] proposed a multiobjective evolutionary design approach for the optimization (m-EDO) of shading devices which are part of the renovation kits of an existing residential building in Madrid. Singh et al. [18] investigated the effect of extended values of shade transmittance on energy and visual performances of the office building. The study has been conducted for Shillong, which can be considered as representative of cold climates in India. Simulations of a number of glazing and internal roller shade combinations have been performed for south, west, north, and east facing offices with varying window sizes, properties of glazing, and shading devices. Eom et al. [19] distinguished between the periods during which shading devices are required and the periods during which they are not necessary by obtaining the Balance Point Temperature using simulations, and they designed shading devices on the basis of the periods separated in such a manner. As a result, they proposed a specification for optimal shading devices within the size range of shading devices, which is determined by the solar altitude, and suggested a quantitative basis for the projection length using annual heating and cooling loads. Kim et al. [20] conducted the analysis of annual cooling and heating loads and the sunshine amount on the living room floor surface using IES 5.5.1 and assessed the effects of movable horizontal shading devices in order to evaluate the impact of a new type of movable horizontal shading device on the indoor thermal environment and solar access performance. Kim et al. [21] conducted the evaluation of the shading coefficient applied to the energysaving building envelope technology of office buildings and the loads of different types of horizontal shading devices according to the orientations, using the e-Quest program, and analyzed the envelope elements according to the orientations. Kim and Yoon [22] performed a quantitative assessment of the various façades considering the physical properties of the envelope components which can be selected in the envelope design, calculated annual loads especially with respect to the combination of windows and fixed external shading devices through simulation, and analyzed the design suitability. Song et al. [23] conducted an analysis of full solar irradiation of the vertical glass surface depending on the length of the horizontal shading device according to the orientations concerning the perimeter boundary in office buildings in Seoul, using a building energy analysis program. Kim [24] conducted a study for deriving improvement methods of solar radiation control standards of windows and shading devices on the basis of the analysis of our country's and other countries' related standards by analyzing the current status of energysaving design standards of buildings of major countries and performing a comparative analysis of them with the national standards and investigated complementary elements for the national standards and necessary amendments of them.

Although such various studies on shading devices were previously conducted, they were carried out before "The Support System for Composition of Green Architectures" was amended in South Korea, so it is difficult to apply the results of the previous studies to actual buildings so that they can meet legal law standards. So, they do not consider applying the shading device for energy saving to other buildings. 
Therefore, it is necessary to conduct research on the design methods of shading devices that meet the revised legal standards by performing analysis of the revised regulations.

\section{Energy Consumption Saving Effectiveness of the Horizontal Shading Device Installation}

In case of large window size, the solar block effect by the shading device was more important than in the case of small window. For confirmation of the effectiveness of energy saving, this study assessed the energy simulation and analyzed the simulation results. So, in this chapter, the authors simulated nonshading device effectiveness and the shading device effectiveness on the regulation level. This is the length requirement of horizontal shading devices for recognition of building permission. Because the purpose of this study is to satisfy building permission, the shading devices must meet the minimum protrusion length of horizontal shading devices.

3.1. Simulation Modeling. A comparison of the performance of windows and shading devices was conducted using COMFEN 4.1, which is a window and daylighting simulation software program provided by Lawrence Berkeley National Laboratory. COMFEN 4.1 is the façade design tool based on the Energy Plus engine and provides a systematic evaluation of various elevations of commercial buildings and offers a simple user interface so that the user can create diverse façade designs. Based on the Energy Plus engine, it offers the figures of energy consumption, peak energy demand, and thermal and visual comfort as a result with respect to a variety of window designs and enables the user to select the optimal window design by providing the results of each design case in the form of a graph or table. Figure 2 shows the COMFEN program interface.

In order to propose a design method, the target space of the peripheral portion of the building was selected, the simulation of the one-year period was conducted, and annual energy consumption was calculated. The simulation input conditions including the unit space and its size are presented in Table 1. With respect to the selection of the unit space, the depth of the room and the floor height were determined by considering the average distance between the pillars and the light environment on the basis of the figures derived from the analysis of the current status of the architecture, and the "Window Design Guidelines for Building Energy Savings (2012)" was referred to during the process. This guideline was published by the "Ministry of Land, Infrastructure and Transport" in South Korea. So, the referenced guideline could help the designer in the application for energy saving. This study uses the weather data at Seoul in Korea. And this data was provided by “The Korean Solar Energy Society." Figure 3 shows the unit space modeling for the energy simulation of BASE case.

3.2. Analysis of the Energy Consumption. BASE case refers to the situation where the horizontal shading device is not installed and simulations were conducted by applying the
TABLE 1: Unit space simulation information.

\begin{tabular}{lc}
\hline & Content \\
\hline Size of room & $6 \mathrm{~m} \times 4.5 \mathrm{~m} \times 2.7 \mathrm{~m}$ \\
Use of the building & Office \\
Air-conditioning system & Packaged single zone \\
& Lighting load: $16 \mathrm{~W} / \mathrm{m}^{2}$ \\
Load conditions & Equipment load: $10 \mathrm{~W} / \mathrm{m}^{2}$ \\
& People: 3 \\
\hline
\end{tabular}

TABLE 2: Design elements for the selection of window simulation.

(a)

\begin{tabular}{lcccc}
\hline \multicolumn{4}{c}{ Content } \\
\hline $\begin{array}{l}\text { Orientation } \\
\text { Window-to-wall }\end{array}$ & East & West & South & North \\
ratio (WWR) & $10 \% \sim 80 \%$ & $10 \% \sim 80 \%$ & $10 \% \sim 80 \%$ & $10 \% \sim 80 \%$ \\
\hline
\end{tabular}

(b)

\begin{tabular}{lcccc}
\hline Window type & Type 1 & Type 2 & Type 3 & Type 4 \\
\hline $\begin{array}{l}U \text {-value } \\
\left(\mathrm{W} / \mathrm{m}^{2} \cdot \mathrm{K}\right)\end{array}$ & 1.8 & 1.8 & 2.1 & 2.1 \\
$\mathrm{SHGC}$ & 0.4 & 0.6 & 0.4 & 0.6 \\
\hline
\end{tabular}

four types of windows to each window-to-wall ratio. Simulations were performed in this manner considering the fact that all buildings do not use identical windows, and four types of windows were selected by referring to the window design guidelines. Applying the four types of windows to each window-to-wall ratio, the annual energy consumption was calculated, and then the averaged figure of energy consumption for each window-to-wall ratio was calculated, and these figures were compared. The design elements for the simulation setup are presented in Table 2. So, the results are presented in Figure 4.

As a result of simulations, it was confirmed that the higher the window-to-wall ratio, the greater the energy consumption. Especially in case of $80 \% \mathrm{WWR}$, the difference of energy consumption between east façade and west façade was confirmed as $27.91 \mathrm{MJ} / \mathrm{m}^{2} \cdot \mathrm{yr}$ (about $4 \%$ ). And the case of south façade and north façade was different, $113 \mathrm{MJ} / \mathrm{m}^{2} \cdot \mathrm{yr}$ (about 18\%). This was a phenomenon that occurred in all orientations, and the fact that as the window-to-wall ratio gets higher the energy consumption for cooling increases may indicate that as the window becomes larger, the indoor heat gain is increased, increasing cooling loads, and the cooling energy consumption is increased.

3.3. Variation of Energy Consumption by Installation of Horizontal Shading Device (Case 1). Installation of the shading device for energy saving is done by various methods. But the regulation of South Korea is to only limit the minimum length of horizontal shading. So, the designer should keep the regulation and guideline for advantage of approval. Therefore, the authors consider regulation of installation of shading devices in an office building. In this chapter, the authors calculated 


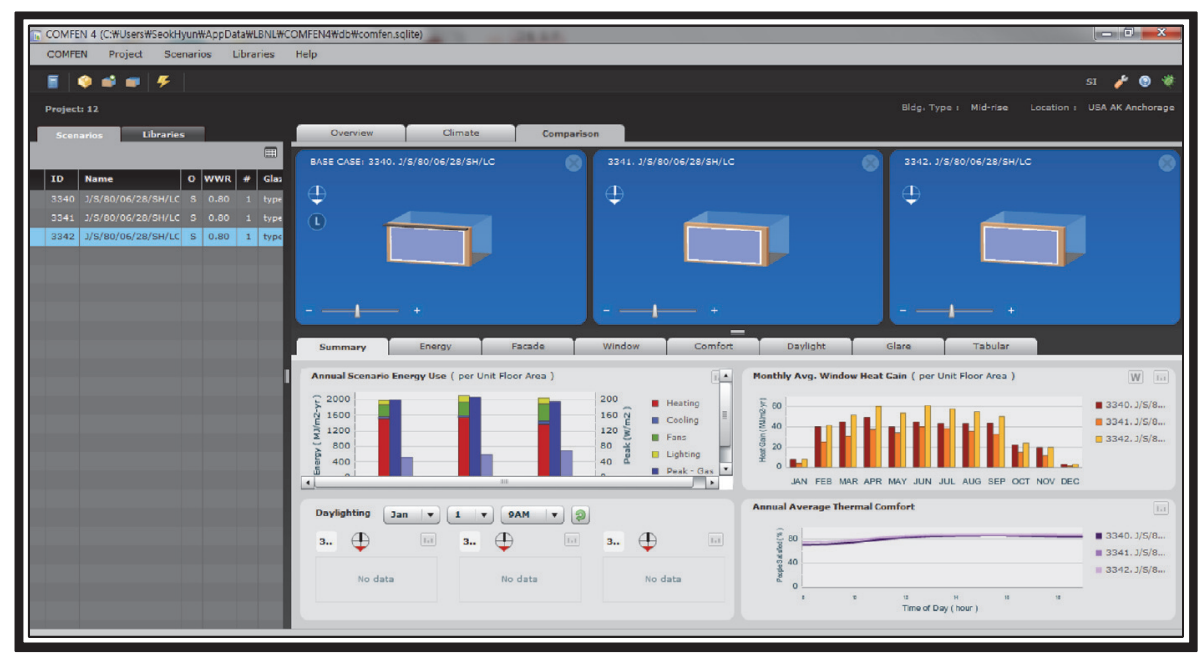

Figure 2: COMFEN.

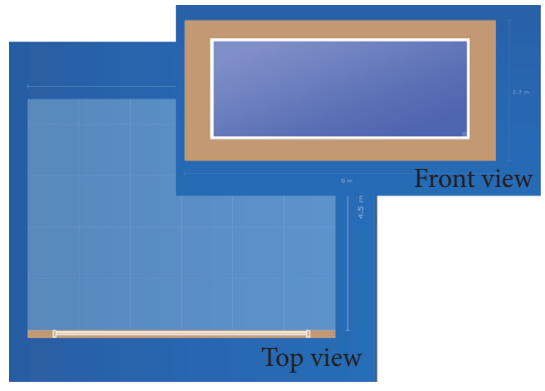

$\langle$ COMFEN modeling $\rangle$

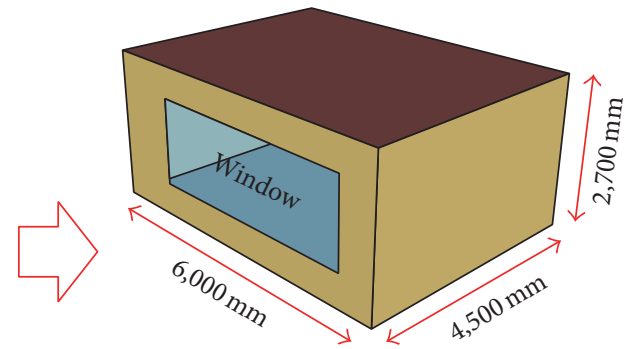

$\langle$ Scheme of standard building modeling $\rangle$

FIGURE 3: Energy simulation modeling by various WWR and orientation (BASE case).

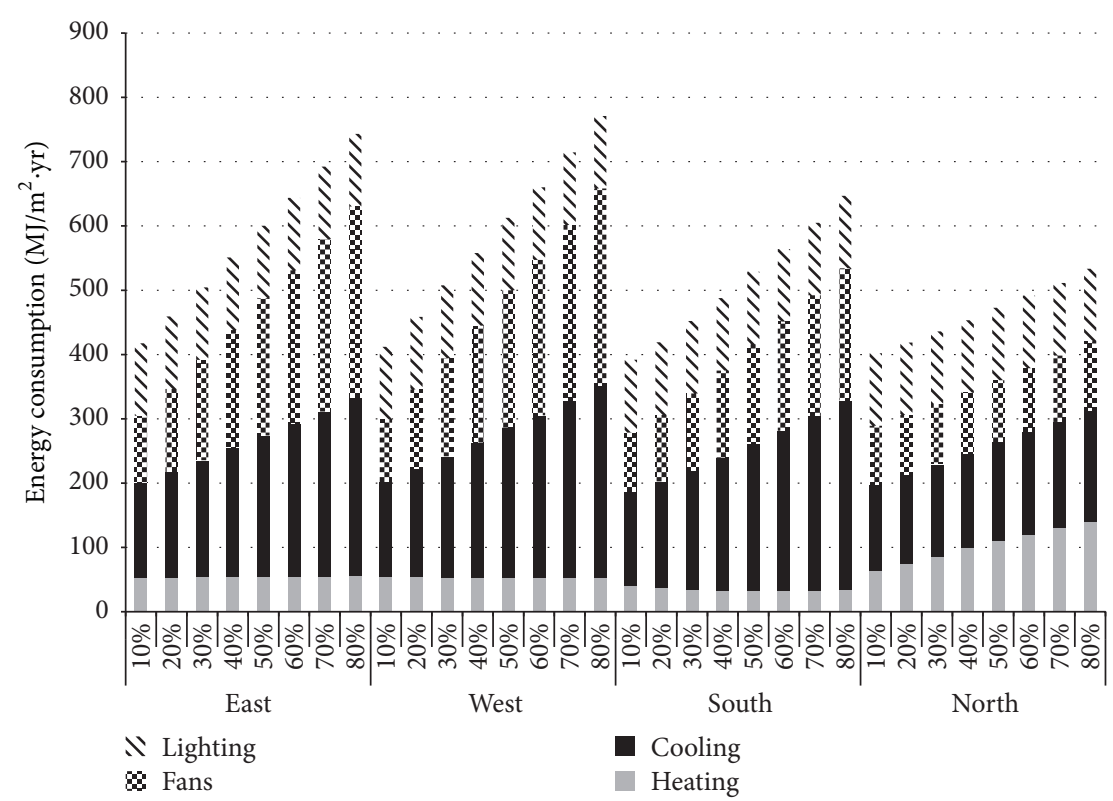

FIGURE 4: Energy consumption by various WWR and orientation (BASE case). 


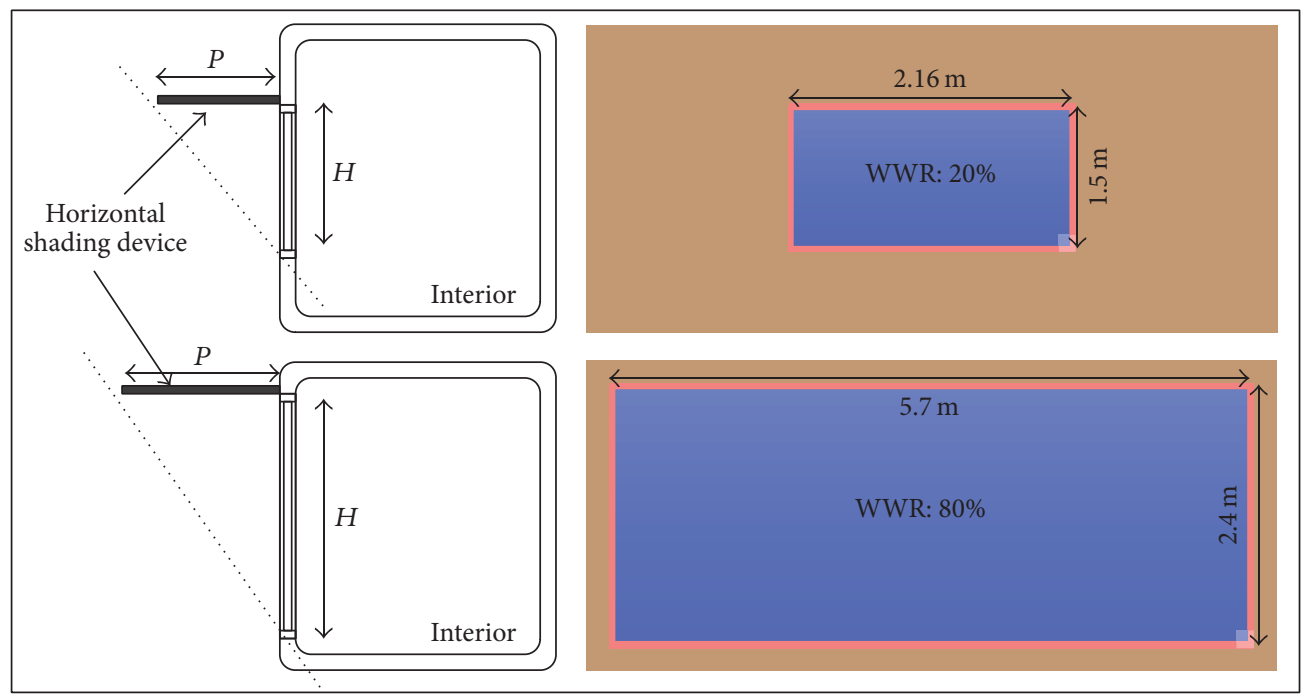

FIGURE 5: Length difference of horizontal shading device by WWR.

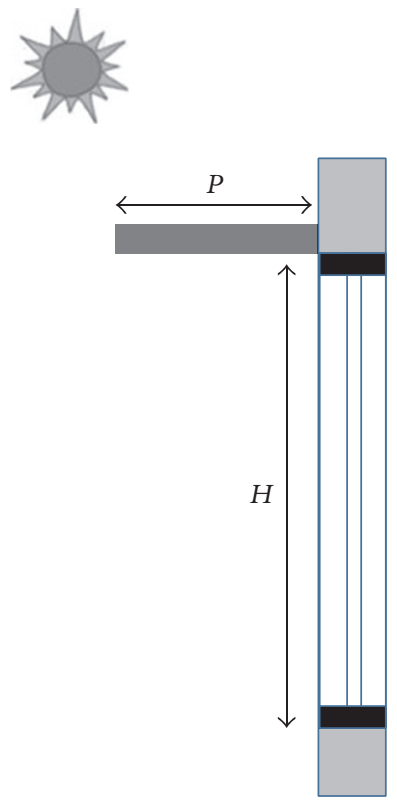

(a) Vertical section

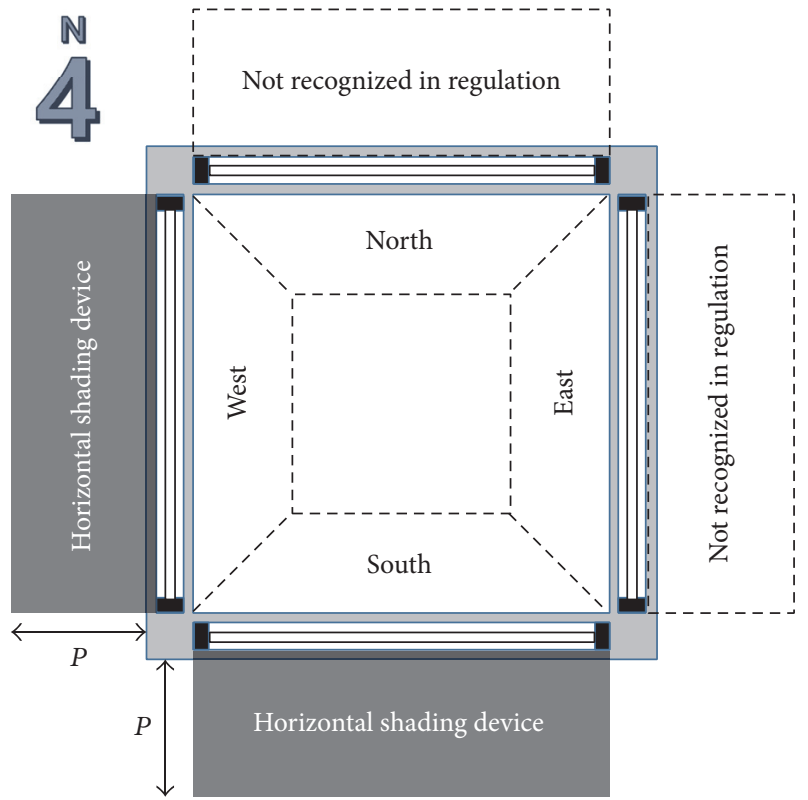

(b) Floor plan

FIGURE 6: Plan view of permission range of horizontal shading device in regulation.

the length of horizontal shading through keeping regulation of South Korea. Figure 5 presented an example of the difference of horizontal shading device by various WWR.

In order to meet the legal criteria, it is necessary to install the horizontal shading device whose solar heat gain coefficient is 0.6 (the value calculated using the formula and table presented in the Energy Performance Index) over south facing and west facing windows. It is possible to get the solar heat gain coefficient using the figure obtained by dividing the protruding length of the horizontal shading device $(P)$ by the length from the horizontal shading device to the bottom end of the floodlight part $(H)$. In this study, the protruding length of the horizontal shading device was determined by assuming that a horizontal shading device was installed over the window. Figure 6 explained the regulation detail about horizontal shading device installation permission.

Depending on the height of each window, if the $P / H$ value is 0.2 or higher, legal standards are satisfied for south windows. The same is also true if $P / H$ value is 0.6 or higher in case of west façade. Thus, the protruding lengths of horizontal shading devices were calculated by the equation below, and Table 3 shows the results. Hence, 
TABLE 3: Protruding lengths of horizontal shading devices in the south and west façade.

\begin{tabular}{lcccc}
\hline WWR & Window height, $W[\mathrm{~m}]$ & Window width, $H[\mathrm{~m}]$ & \multicolumn{2}{c}{ The protruding length, $P[\mathrm{~m}]$} \\
West façade \\
\hline $10 \%$ & 1.4 & 1.2 & 0.24 & 0.72 \\
$20 \%$ & 2.16 & 1.5 & 0.3 & 0.9 \\
$30 \%$ & 2.7 & 1.8 & 0.36 & 1.08 \\
$40 \%$ & 3.6 & 1.8 & 0.36 & 2.42 \\
$50 \%$ & 3.9 & 2.1 & 0.42 & 2.1 \\
$60 \%$ & 4.6 & 2.1 & 0.48 & 2.4 \\
$70 \%$ & 4.7 & 2.4 & 0.48 & 2.4 \\
$80 \%$ & 5.7 & 2.4 & & 0.4 \\
\hline
\end{tabular}

$\frac{\text { length of horizontal shading device }(P)}{\text { vertical length from horizontal shading device to end of window }(H)}$,
$P \geq 0.2 \times H$,
$P \geq 0.6 \times H$.

The protruding length of the horizontal shading devices which can receive the scores of the Energy Performance Index was calculated for south and west windows. For south windows, the calculated protruding length was practically applicable, but in the case of west windows, the calculated protruding length to get the scores of the Energy Performance Index was longer than $1 \mathrm{~m}$ in some cases, so structural problems may occur in practical application. In addition, there may also be a problem of indoor illumination because of reduction of incoming daylight. However, since the energy consumption was computed by simulation in this study, the indoor energy consumption for one year was calculated by applying the derived figure of the protruding length. The results are presented in Figure 7.

As a result of the simulation, it was confirmed that the higher the window-to-wall ratio, the greater the energy consumption. The same results were obtained for west and south windows, and the installation of the horizontal shading device blocked the incoming solar radiation which increased the cooling load of the room and made it possible to get the Energy Performance Index scores. For west façade, the energy-saving ratio was shown to be $2 \sim 16 \%$ by increasing WWR. In particular, the heating energy consumption increased by approximately $30.24 \mathrm{MJ} / \mathrm{m}^{2} \cdot \mathrm{yr}$, the energy consumption for cooling and fans decreased by about $75.52 \mathrm{MJ} / \mathrm{m}^{2} \cdot \mathrm{yr}$ and by about $75.78 \mathrm{MJ} / \mathrm{m}^{2} \cdot \mathrm{yr}$, respectively, and the total energy consumption was reduced by about $124.06 \mathrm{MJ} / \mathrm{m}^{2} \cdot \mathrm{yr}$ in case of WWR $80 \%$. However, due to the excessive protruding length of the shading devices, insufficient daylight enters the room, and thereby the use of indoor lighting seems necessary and structural problems may occur. In case of south window, the energy-saving ratio was increasing by $1 \sim 13 \%$. And the heating energy consumption was slightly increased by about $9.40 \mathrm{MJ} / \mathrm{m}^{2} \cdot \mathrm{yr}$, but the energy consumption for cooling and fans decreased by about $49.10 \mathrm{MJ} / \mathrm{m}^{2} \cdot \mathrm{yr}$ and by about $42.01 \mathrm{MJ} / \mathrm{m}^{2} \cdot \mathrm{yr}$, respectively, and the total energy consumption decreased by about $81.71 \mathrm{MJ} / \mathrm{m}^{2} \cdot \mathrm{yr}$ in case of WWR $80 \%$.

The horizontal shading devices must be installed at the time of construction or remodeling of buildings and their installation makes it possible to reduce the energy consumption by lowering the cooling load. However, if excessive shading devices result in the lack of sunlight coming into the room, lighting energy is consumed and the energy-saving effect is decreased.

The review of previous results showed that the solar heat gain was reduced by installing horizontal shading devices and overall energy consumption was decreased. However, indoor intensity of illumination may be reduced by blocking incoming daylight. To verify this, indoor intensity of illumination was examined by using the Daylight 3D Contour provided by the simulation COMFEN 4.1. Simulations were performed by differentiating window area ratios of $3 \mathrm{D}$ Contour so that they became $20 \%, 40 \%, 60 \%$, and $80 \%$, and the results were compared. When window area ratios were differentiated by $10 \%$, the differences in the indoor illumination were not noticeable, so they were differentiated by $20 \%$. Since horizontal shading devices are installed as the means for reducing cooling loads of the summer months, July was set as the simulation period.

It was confirmed by simulations that the higher the window area ratio is, the higher the indoor intensity of illumination is, and when the standard office illumination is considered in terms of the standard of intensity of illumination of KS A 3011:1988, about 400 600 lx is regarded as the proper intensity of illumination, which is the brightness which allows us to see the keyboards in the office. In rooms with south windows, it was bright in the morning, at noon, and in the 


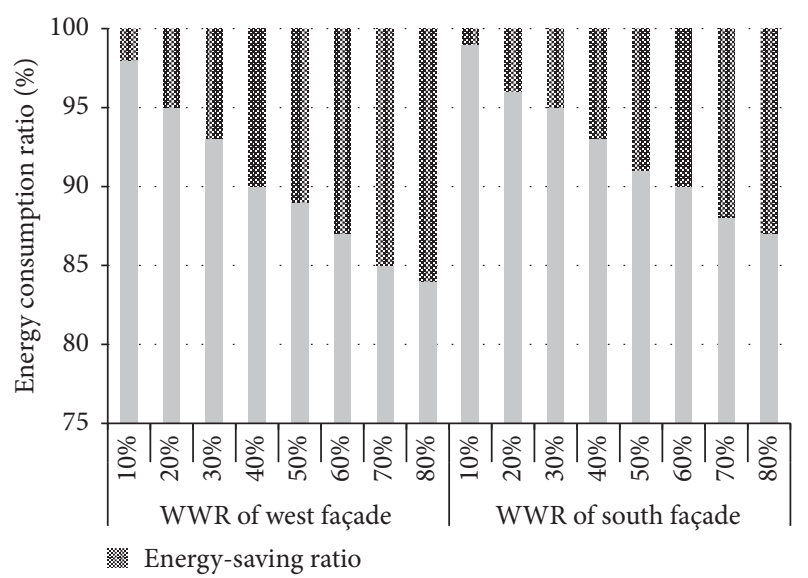

FIGURE 7: Energy consumption saving rate by installation of horizontal shading device (Case 1).

afternoon. In rooms with west windows, incoming daylight was the greatest in the morning and in the afternoon, but the use of lighting is considered necessary for the indoor working environment in both rooms with south windows and the ones with west windows.

\section{Improvement Suggestion about Design of Horizontal Shading Device}

4.1. Proposed Design of Horizontal Shading Device Including Lighting Control (Case 2). When the horizontal shading device that meets the legal criteria was applied, incoming solar radiation was reduced and the indoor cooling load was consequently reduced, but the indoor intensity of illumination was not appropriate for the work environment of the person in the room. Therefore, lighting energy was used to maintain a certain level of indoor intensity of illumination, and consequently energy consumption occurred. In order to resolve the indoor illumination problems caused by the installation of horizontal shading devices, a method of lighting control was applied which makes it possible to reduce lighting energy consumption while keeping the indoor illumination suitable for the work environment of the person in the office. As the lighting control method, Stepped Control, which is provided by the simulation program COMFEN 4.1, was selected. Stepped Control is a lighting control method in which the input power is changed depending on the daylight intensity and the intensity of illumination can be adjusted in three stages. In order to conduct a comparison of the energy consumption of Case 2, the case where the horizontal shading device is installed which can get the Energy Performance Index scores, and the case where lighting control is added to CASE 1, the simulation of Case 2 was performed. In order to compare the energy consumption before and after applying the lighting control, the energy consumption of Case 2 was compared with that of Case 1 which involves the application of the horizontal shading device which satisfies the regulatory standards, and the results are presented in Figure 8.

Figure 8 shows that energy consumption reduced through lighting control. In case of keeping the regulation

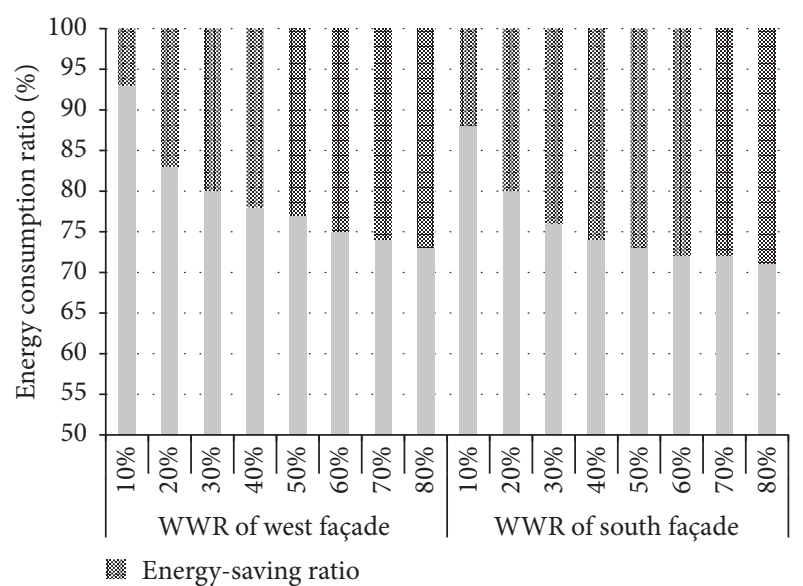

FIGURE 8: Energy consumption saving rate by installation of horizontal shading device and lighting control (Case 2).

about the installation of horizontal shading devices, the designer should consider lighting control for energy saving. So, the illumination of the room was enough. For that reason, the energy consumption of lighting and the system energy consumption of internal load were reduced by lighting control. Since the lighting energy consumption was just reduced by the application of lighting control, the total energy consumption was reduced by approximately maximum $29 \%$ in south façade and $27 \%$ in west façade.

4.2. Proposed Design of Horizontal Shading Device by Green Building Certification Criteria (Case 3). Not only for west and south windows related to the scores of Energy Performance Index, but also for east and north windows, simulation was performed to determine the effect of the installation of horizontal shading devices. The derived protruding length of the horizontal shading device is suitable for actual application if the window faces south, but if the window faces west, a structural problem may arise during the installation or the room may become dark due to the reduction of incoming daylight because the protruding length of the shading device is longer than $1 \mathrm{~m}$. Therefore, referring to the Green Building Certification Standards, the protruding length of the horizontal shading device was calculated as presented in Table 4.

The shape of the window was designed in a common rectangular shape of which the horizontal sides are longer than the vertical ones, and the length of the horizontal shading device applied to each window was determined using the following formula:

$$
\begin{aligned}
& P=H \div \tan A, \\
& A=\text { Latitude }-90+23.7 .
\end{aligned}
$$

Here, $P$ is the protruding length of the horizontal shading device, $H$ is the vertical height of the window, and Latitude refers to the latitude of Seoul, $37.3^{\circ}$.

Using the protruding length of the horizontal shading device and the solar heat gain coefficient formula proposed in the Energy Performance Index, it was checked whether 


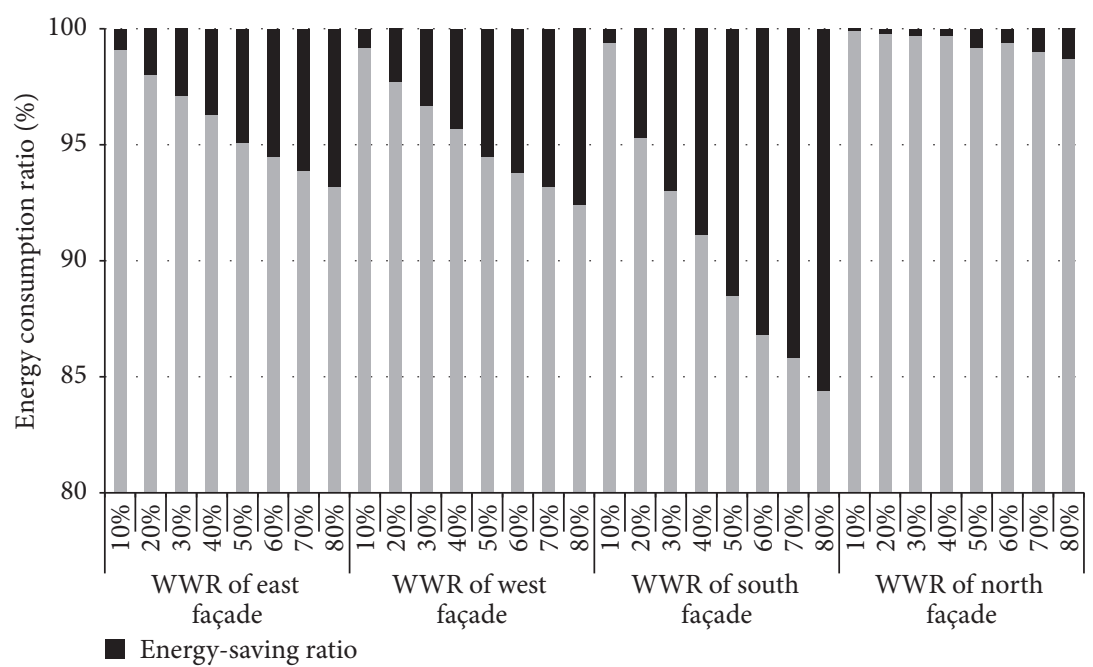

FIGURE 9: Energy consumption saving rate by Case 3.

TABLE 4: Protruding lengths difference of horizontal shading devices in the south façade.

\begin{tabular}{lcc}
\hline WWR & \multicolumn{2}{c}{ The protruding length, $P[\mathrm{~m}]$} \\
& Case $1[\mathrm{~m}]$ & Case 3 $[\mathrm{m}]$ \\
\hline $10 \%$ & 0.24 & 0.3 \\
$20 \%$ & 0.3 & 0.4 \\
$30 \%$ & 0.36 & 0.45 \\
$40 \%$ & 0.36 & 0.45 \\
$50 \%$ & 0.42 & 0.55 \\
$60 \%$ & 0.42 & 0.55 \\
$70 \%$ & 0.48 & 0.6 \\
$80 \%$ & 0.48 & 0.6 \\
\hline
\end{tabular}

the derived protruding length of the horizontal shading device can meet regulatory standards and get points. Since the points are currently given for south and west windows, calculations were conducted for south and west windows, and, consequently, it was confirmed that although no scores can be acquired for west windows, it is possible to get points in case of south windows for every window-to-wall ratio. The protruding lengths of horizontal shading devices were calculated again, and simulations were conducted for all four orientations as explained above, and this simulation case was referred to as Case 3 for convenience. In order to confirm the effect of the installation of the horizontal shading device, a comparison of the energy consumption of Case 3 and BASE, the case where the shading device was not installed, was conducted, and the results are presented in Figure 9.

The comparison of BASE and Case 3 showed that when the horizontal shading device is installed, overall energy consumption is reduced as presented in Figure 9. In other words, when the horizontal shading device is installed, the case of increasing WWR, the authors confirmed that the energy consumption saving ratio was decreased. In case of north façade, energy consumption saving ratio was confirmed to be $0.1 \sim 1.3 \%$. With these results, the effect of the shading device installation was hard to expect in north façade. West façade and east façade showed energy-saving ratios of $0.8 \sim 7.6 \%$ and $0.9 \sim 6.8 \%$. So, the authors confirmed the effect of extended horizontal shading device at the west and east façade. Actually, the case of south façade was the most effective by simulation results. The energy consumption saving ratio was shown to be $0.6 \sim 15.6 \%$ by difference of WWR. Although the reduction of energy consumption by the installation of the horizontal shading device was expected, blocking the daylight entering the room may cause a problem in the indoor intensity of illumination. Therefore, for the appropriate indoor environment, indoor lighting control is required.

\section{Conclusion}

As a result of the revision of "The Support System for Composition of Green Architectures" in May 2015, it has become necessary to get required scores for certain items of EPI (Energy Performance Index) for buildings in relation to the Design Standards for Building Energy Savings when some of the public buildings with a total gross floor area of $3,000 \mathrm{~m}^{2}$ or more than $3,000 \mathrm{~m}^{2}$ are built or remodeled in South Korea. Although the current Energy Performance Index provides evaluation methods for the installation of horizontal shading devices, it does not describe the design methods of horizontal shading devices and does not present established legal criteria for them. Therefore, this study proposed a method that may be helpful when designing a horizontal shading device.

For each window-to-wall ratio, energy consumption of the window without a horizontal shading device was analyzed. The higher the window-to-wall ratio was, the larger the energy consumption was, but lighting energy consumption was the same in cases of all window-to-wall ratios, and differences of heating energy consumption were minimal. However, it was confirmed that the energy consumption increase 
caused by the use of fans and air-conditioning resulted in the increase of the total energy consumption.

Energy consumption was calculated both for the room without the horizontal shading device and for the one with the horizontal shading device after the protrusion length which can get scores of the Energy Performance Index was calculated and applied. Then, the figures of indoor energy consumption were compared. The lighting energy consumption was constant regardless of whether the horizontal shading device was applied or not, but heating energy consumption increased due to the application of the horizontal shading device. However, since the application of the horizontal shading device resulted in blocking incoming solar radiation, the amount of the decrease of energy consumption for fans and cooling was higher than the amount of the increase of energy consumption for heating, and the total energy consumption was reduced. In addition, it was found that the higher the window-to-wall ratio was, the greater the amount of energy consumption reduction was.

Although it was confirmed that cooling loads and the energy consumption for cooling and fans are reduced by blocking incoming solar radiation if the horizontal shading device is installed, the reduction of incoming solar radiation may cause problems with the indoor illumination. Thus, the illumination of indoor room was compared in the case of no installed shading device and the case of installed shading device. As a result, it was confirmed that as the protruding length of the horizontal shading device becomes longer, the incoming solar radiation is reduced, the indoor intensity of illumination is lowered, and lighting energy consumption becomes greater in the room to which horizontal shading device is applied than in the room without the horizontal shading device. Therefore, in this study, after the horizontal shading device was applied, lighting control was additionally applied and simulation was conducted. Consequently, it was confirmed that the total energy consumption is decreased since energy consumption is reduced by the application of the horizontal shading device and lighting energy consumption is additionally reduced by application of lighting control.

The current Energy Performance Index gives scores to the shading devices for west and south windows. But in Chapter 9 of 2009 ASHRAE Handbook-Fundamentals, the "arrival complaints" are said to be the worst immediately after the office occupant comes to work in the morning because of the thermal unpleasantness which occurs when they arrive in the space. Since east windows also have the potential to reduce cooling loads in addition to west and south ones, simulation was conducted for the case where the horizontal shading device is installed at the east window. As a result, it was found that when a horizontal shading device of the same length was installed over the east and west window, the amount of energy consumption was similar, and the amount of energy consumption reduction was also similar. Therefore, it is thought to be necessary to consider giving the Energy Performance Index scores not only to shading devices for west or south windows but also to those for east windows. On the basis of such considerations, an improved design method of the horizontal shading device was proposed.

\section{Competing Interests}

The authors declare that there are no competing interests regarding the publication of this paper.

\section{Acknowledgments}

This work was supported by the 2015 Yeungnam University Research Grant (215A580024).

\section{References}

[1] Ministry of Land, "Infrastructure and Transport announced, Enforcement degree of The support System for composition of Green Architectures," 2015.

[2] Ministry of Land, "Infrastructure and transport announced," in Enforcement Rule of The Support System for Composition of Green Architectures, p. 3, 2015.

[3] Ministry of Land, Infrastructure and Transport Announced, Regulation of Improved Energy Performance of Existing Building, Ministry of Land, 2015.

[4] Ministry of Land, "Infrastructure and Transport announced," Energy-Saving Design Criteria, 2015.

[5] Ministry of Land, Infrastructure and Transport Announced, Energy-Saving Design Criteria, 2015.

[6] Korea Infrastructure Safety and Technology Corporation, A Study on the Design and Construction Guideline about the Solar Control Device Type Variation, 2014.

[7] N. A. Al-Tamimi and S. F. S. Fadzil, "The potential of shading devices for temperature reduction in high-rise residential buildings in the tropics," Procedia Engineering, vol. 21, pp. 273-282, 2011.

[8] G. Kim, H. S. Lim, T. S. Lim, L. Schaefer, and J. T. Kim, "Comparative advantage of an exterior shading device in thermal performance for residential buildings," Energy and Buildings, vol. 46, pp. 105-111, 2012.

[9] A. I. Palmero-Marrero and A. C. Oliveira, "Effect of louver shading devices on building energy requirements," Applied Energy, vol. 87, no. 6, pp. 2040-2049, 2010.

[10] G. Datta, "Effect of fixed horizontal louver shading devices on thermal perfomance of building by TRNSYS simulation," Renewable Energy, vol. 23, no. 3-4, pp. 497-507, 2001.

[11] S.-H. Kim, K.-J. Shin, B.-E. Choi, J.-H. Jo, S. Cho, and Y.-H. Cho, "A study on the variation of heating and cooling load according to the use of horizontal shading and venetian blinds in office buildings in Korea," Energies, vol. 8, no. 2, pp. 1487-1504, 2015.

[12] D.-S. Lee, J.-H. Jo, S.-H. Koo, and B.-Y. Lee, "Development of climate indices using local weather data for shading design," Sustainability, vol. 7, no. 2, pp. 1884-1899, 2015.

[13] M. Kim, S.-B. Leigh, T. Kim, and S. Cho, "A study on external shading devices for reducing cooling loads and improving daylighting in office buildings," Journal of Asian Architecture and Building Engineering, vol. 14, no. 3, pp. 687-694, 2015.

[14] A. Tzempelikos and A. K. Athienitis, "The impact of shading design and control on building cooling and lighting demand," Solar Energy, vol. 81, no. 3, pp. 369-382, 2007.

[15] J. Choi, T. Lee, E. Ahn, and G. Piao, "Parametric louver design system based on direct solar radiation control performance," Journal of Asian Architecture and Building Engineering, vol. 13, no. 1, pp. 57-62, 2014. 
[16] L. Karlsen, P. Heiselberg, I. Bryn, and H. Johra, "Solar shading control strategy for office buildings in cold climate," Energy and Buildings, vol. 118, pp. 316-328, 2016.

[17] M. Khoroshiltseva, D. Slanzi, and I. Poli, "A Pareto-based multiobjective optimization algorithm to design energy-efficient shading devices," Applied Energy, vol. 184, pp. 1400-1410, 2016.

[18] R. Singh, I. J. Lazarus, and V. V. N. Kishore, "Effect of internal woven roller shade and glazing on the energy and daylighting performances of an office building in the cold climate of Shillong," Applied Energy, vol. 159, pp. 317-333, 2015.

[19] J. Y. Eom, W. K. Choi, and S. J. Suh, "A theoretical study on the optimal design of a overhang shading device based on balance point temperature," Journal of Architectural Institute of Korea Conference, vol. 25, no. 1, pp. 235-238, 2005.

[20] M. H. Kim and S. J. Suh, "A study on design of movable horizontal shading device for office building," Journal of the Korean Solar Energy Society, vol. 28, no. 2, pp. 50-57, 2008.

[21] D. K. Kim, G. Yun, K. C. Yoon, S. S. Kim, and K. S. Kim, "A study for cooling o heating load reduction in office space with the change of overhangs length and shading coefficient," Journal of Korean Institute of Architectural Sustainable Environment and Building Systems, vol. 4, no. 3, pp. 127-134, 2010.

[22] J.-A. Kim and S.-H. Yoon, "A study on exterior horizontal louvers of office space to reduce heating, cooling and lighting loads," Journal of the Architectural Institute of Korea Planning \& Design, vol. 28, no. 10, pp. 345-352, 2012.

[23] S. W. Song and D. W. Cho, "An analysis of global radiation on vertical windows with external horizontal shadings," Journal of Architectural Institute of Korea Spring Conference, vol. 34, no. 1, pp. 233-234, 2014.

[24] S. Kim, "Improvement of window and shading criteria for reducing solar gain by analysis of Korean and foreign building codes," Journal of Korean Institute of Architectural Sustainable Environment and Building Systems, vol. 9, no. 5, pp. 301-308, 2015. 

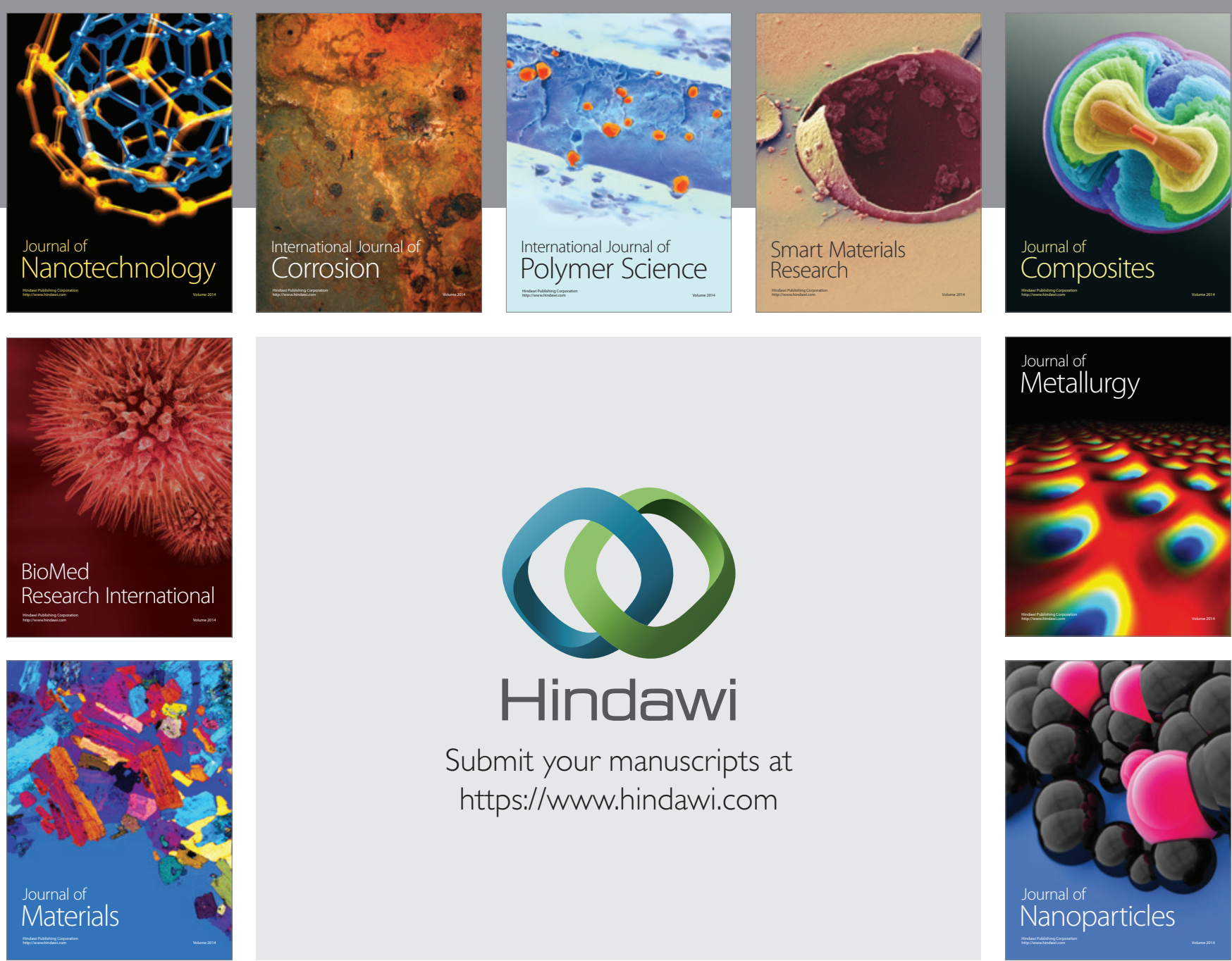

\section{Hindawi}

Submit your manuscripts at

https://www.hindawi.com

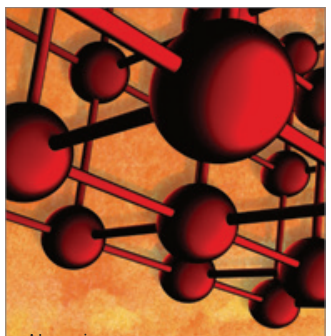

Materials Science and Engineering
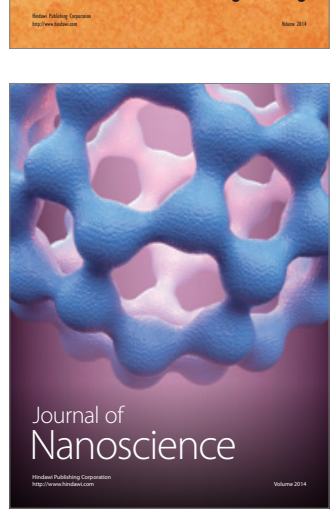
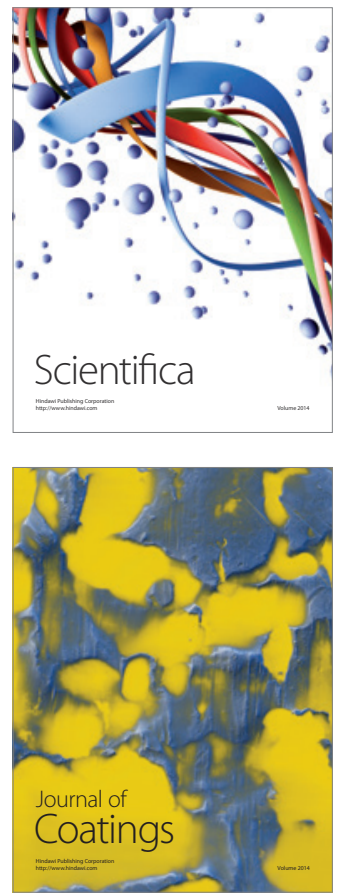
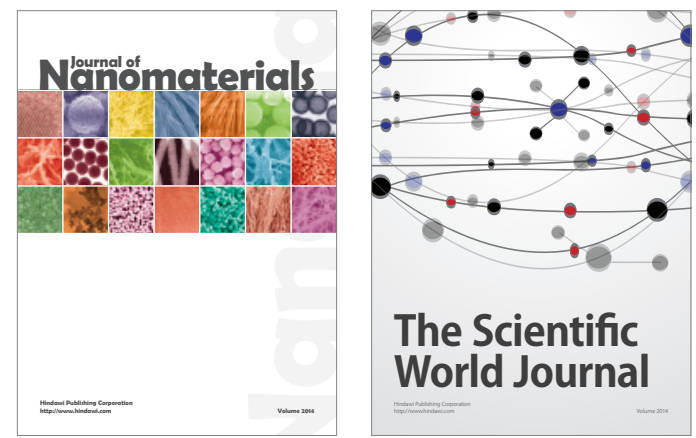

The Scientific World Journal
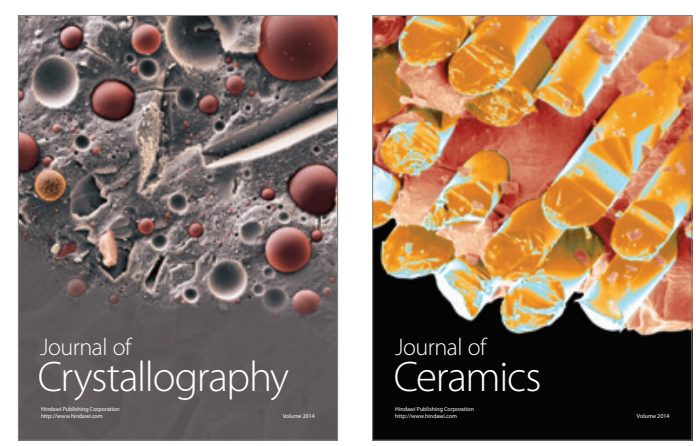
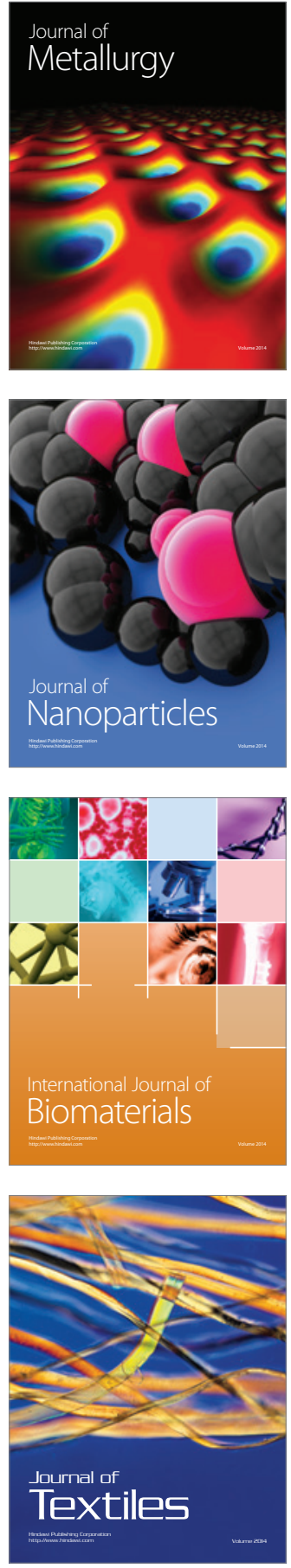